Portland State University

PDXScholar

7-1-2011

\title{
Sustainable Oxygen: A low power approach for providing emergency medical oxygen for spacecraft and hospitals in developing countries
}

Anndee L. Huff

Evan Rhead

Zdenek Zumr

Evan A. Thomas

Portland State University

Follow this and additional works at: https://pdxscholar.library.pdx.edu/mengin_fac

Part of the Systems Engineering Commons

Let us know how access to this document benefits you.

\section{Citation Details}

Huff, A., Rhead, E., Zumr, Z., Thomas, E., Sustainable Oxygen: A low power approach for providing emergency medical oxygen for spacecraft and hospitals in developing countries, International Conference on Environmental Systems, Portland, Oregon, 2011

This Article is brought to you for free and open access. It has been accepted for inclusion in Mechanical and Materials Engineering Faculty Publications and Presentations by an authorized administrator of PDXScholar. Please contact us if we can make this document more accessible: pdxscholar@pdx.edu. 


\title{
Sustainable Oxygen: \\ A low power approach for providing emergency medical oxygen for spacecraft and hospitals in developing countries
}

\author{
Anndee L. Huff ${ }^{1}$, Evan Rhead ${ }^{2}$, Zdenek Zumr, BSME $^{3}$, Evan A. Thomas, Ph.D., P.E. ${ }^{4}$ \\ Portland State University, Portland, Oregon, 97201
}

\begin{abstract}
An oxygen concentrator targeting an $80 \%$ reduction in power demand over commercial systems is being developed using a pressure swing adsorption process. This system is targeted for a service interval five times longer than commercial systems, and is tolerant to high humidity environments - the leading cause of device failure in developing countries. This system could provide emergency medical oxygen in a spacecraft without increasing oxygen concentration in the vehicle. Flight surgeons seek this capability, but presently, there is no system that meets power, size, and delivery rate requirements. This type of system is also well suited for medical oxygen in hospitals in developing countries. Pneumonia accounts for 5\% of all childhood deaths in Africa, and a lack of medical oxygen contributes to mortality rates. This new approach involves a high flow - low power - low purity device. The process proposes a regenerative blower instead of a piston compressor, a humidity tolerant sorbent, and a non-traditional separation cycle.
\end{abstract}

$\begin{array}{ll}\text { CMS } & \text { Nomenclature } \\ \text { LPM } & =\text { Liters Per Minute } \\ \text { PSA } & =\text { Pressure Swing Adsorption } \\ \text { VPSA } & =\text { Vacuum Pressure Swing Adsorption }\end{array}$

\section{Introduction}

Concentrated oxygen is essential in many medical situations. The current commercially available portable oxygen concentrators can produce $93 \%$ oxygen at 33 liters per minute (LPM). However, not only are these systems expensive and delicate, but they contain piston compressors resulting in a high energy demand which proves problematic in certain environments. Instead, this paper presents a proposed oxygen concentration system with the target goal of 40-50\% oxygen purity at a flow rate of 6 LPM (Figure 1). This design may be more sustainable in emergency medical situations ranging from back-up medical device for manned space flight to rural communities in developing countries, both of which require durable low power medical technologies.

Currently, there is no system that meets the requirements of power, size and flow rate needed for use in manned space flight. For an oxygen-generating machine to be suited for manned space flight, it needs to utilize oxygen from surrounding air, not heavy, problematic oxygen storage tanks. ${ }^{1}$ Flight surgeons seek the use of an oxygen concentrator that meets these requirements, especially in emergency situations. ${ }^{2}$ Former NASA Astronaut David Hilmers, M.D., relayed to the authors that, "I have first-hand experience with patients who would benefit from medical oxygen, but lack access to an oxygen system." The design of this oxygen concentrator will not increase the overall oxygen concentration of the vehicle, which helps avoid other complications during flight. A source to power oxygen concentrators has also been a concern. One possible source of power for portable oxygen concentrators is battery power. ${ }^{3}$ Low energy demand concentrators will allow for longer access to concentrated oxygen. Also, previous research sponsored by NASA have shown that improvement of medical emergency

${ }^{1,}$ Undergraduate Student, Environmental Engineering, Portland State University, 1930 SW $4^{\text {th }}$ Avenue, Suite 200

${ }^{2}$ Undergraduate Student, Mechanical and Materials Engineering, Portland State University, 1930 SW $4{ }^{\text {th }}$ Avenue, Suite 400 Graduate Student, Electrical and Computer Engineering, Portland State University, $1930 \mathrm{SW} 4^{\text {th }}$ Avenue, Suite 160

4 Assistant Professor, Mechanical and Materials Engineering, Portland State University, 1930 SW $4^{\text {th }}$ Avenue, Suite 400 , Portland, Oregon 97201, AIAA Member MB. 
procedures in space is of high importance. ${ }^{4}$ Access to a reliable oxygen concentrator would aid in these efforts. Beyond medical applications in manned space flight, a sustainable design also has potential use in developing countries hospitals where reliable power delivery can't be counted on.

It is frequently the case that medical equipment donated to developing countries fails within months. ${ }^{5}$ In the case of oxygen concentrators, piston compressors often fail due to high levels of humidity. When a system does fail, technicians in developing countries lack the expertise, ability to read foreign manuals, or necessary parts to fix the units. ${ }^{6}$ Consistent source of power is also a challenge for hospitals in developing countries. Oxygen concentrators have a high energy demand. In situations of fluctuating power a concentrator can prematurely fail. The sustainable design of this system is to accommodate these issues of extreme environments.

Key to the sustainable design is the choice of materials. The components used in this design have been chosen according to availability, cost and durability. In addition, the design is simple, utilizing standard parts and therefore easy to maintain and repair. This gives the system the robustness to remain operational under less than ideal conditions and variety of environments.

\section{Background}

\section{A. PSA Systems}

Pressure swing adsorption (PSA) systems are used on large scales to supply entire hospitals with oxygen. ${ }^{7}$ The most efficient method of producing oxygen levels higher than $93 \%$ on a large scale is using a piston compressor, small adsorption beds and fast cycles. A study from the University of Singapore describes the fundamental concept of a PSA system as "The basic principle behind adsorption separation processes is that in a process stream of mixed gases, one component (or a group of related components) is preferentially adsorbed over the others." ${ }^{\prime 8}$ The adsorption beds of oxygen concentrators typically consist of zeolite which selectively uptakes nitrogen at high pressures and releases it at low pressures. Oxygenated air is produced when the zeolite captures nitrogen, allowing oxygen to pass through. The pressure ratio needed for adsorption and regeneration is three or more to one. Two beds allow for one bed to absorb while the other desorbs resulting in a constant flow of concentrated oxygen.

Vacuum-pressure swing absorption (VPSA) systems are also occasionally used to supply oxygen. The pressure ratio is achieved using a vacuum pump, allowing for a lower high pressure during the adsorption cycle. The dual bed system is similar to that of the PSA system.

The innovative design of the oxygen concentrator proposed in this paper substitutes carbon molecular sieve (CMS) for zeolite. The CMS captures oxygen, instead of the nitrogen. The oxygen is then harvested during the depressurization phase.

The energy demand of commercial PSA systems is in the compressor, which uses the vast majority of the total energy. In addition, the compressor cost is over $80 \%$ of the total system costs. Any system that uses piston compressors is likely to have similar power uses and system cost.

A PSA system using a regenerative blower in place of a piston may result in a more energy efficient way to compress air, in addition to producing less waste heat. A series of regenerative blowers in conjunction with a vacuum pump can be utilized to reach the necessary desorption pressure difference. Modifying pressure levels, length and diameter of the desiccant beds and the duration of cycles will lead to different concentrations of oxygen.

\section{B. Regenerative Blower}

Regenerative blowers used during the pressurization stage contain impeller blades that draw air into the blower. Using centrifugal forces, the air is accelerated out and forward. The air is then forced by the annular shape of the frame towards the base of the blades and outwards again. Each cycle creates more pressure.

Once enough pressure has been accumulated, the air is diverted out. Regenerative blowers can be used in series to create the desired pressure.

One of the beneficial characteristics of regenerative blowers is fewer moving parts compared to a compressor, which gives a regenerative blower a longer lifespan, lower power consumption and more durability to extreme environmental conditions. The design of regenerative blowers also produces less noise, an important factor in hospital environments.

The test apparatus does not utilize a regenerative blower, it is being used to experimentally determine ideal performance parameters for a regenerative blower component. 


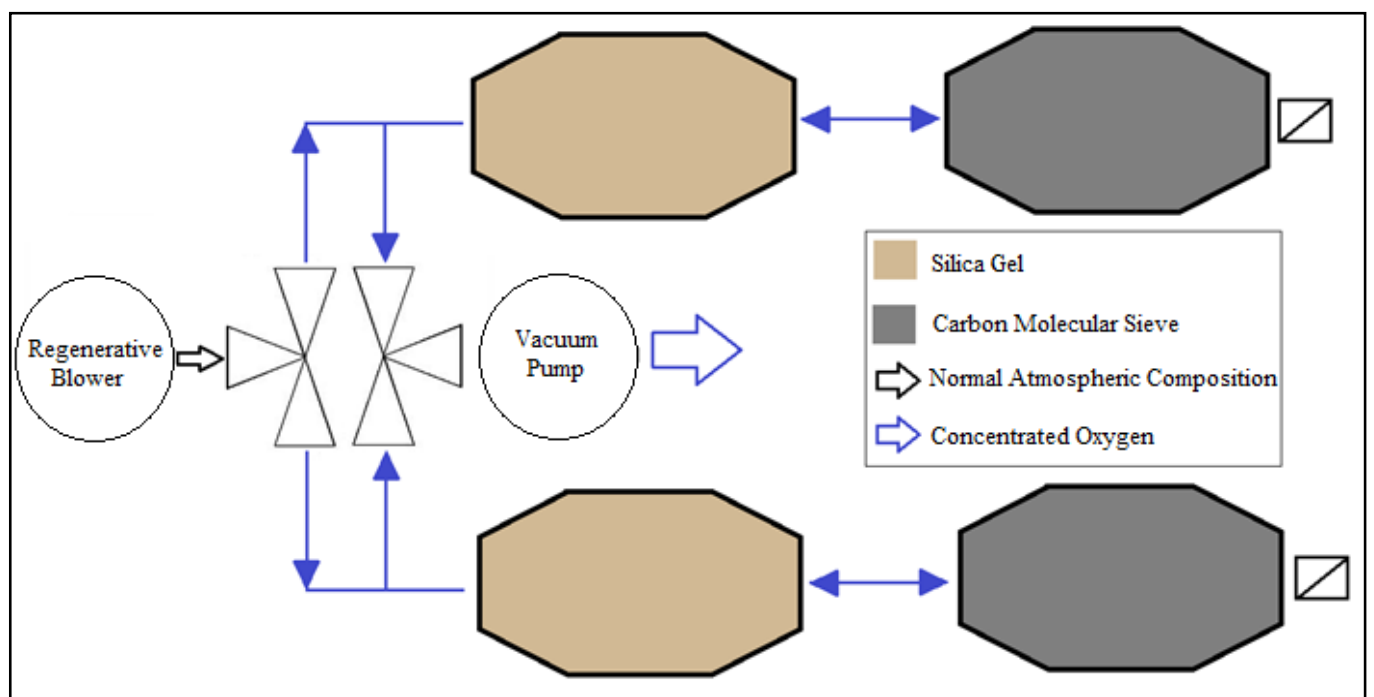

Figure 1: A representation of the proposed VPSA system. The regenerative blower pressurizes air from the atmosphere into the beds of silica gel and carbon molecular sieve, which adsorb water vapor and oxygen, respectively. Nitrogen and other trace gases exit through a check valve. Once the desiccant becomes saturated, a valve switches the flow of pressurized air into the second set of beds. The first set of beds are depressurized with a vacuum pump, regenerating the desiccants. The resulting exhaust from the vacuum pump is oxygenated air and water vapor.

\section{Silica Gel}

An important stage in the PSA system is the removal of moisture from the compressed air. If moisture levels are too high, zeolite or CMS become saturated with water vapor. Types of moisture adsorbents include activated alumina, silica gel and molecular sieve. Characteristics of silica gel make it ideal for this application.

Silica gel desiccant, which is derived from sodium silicate, adsorbs water vapor by attracting the water molecules to the inside of its bead-shaped desiccant structure. The beads are composed of a network of ridged, interconnected, microscopic pores. The large surface area allows for rapid absorption of water, while remaining noncorrosive. Unlike other adsorbents, it does not chemically bond to the adsorbed water or create byproducts, keeping it non-toxic and odorless. It has the strongest affinity to water; however, it can adsorb other substances as well, such as carbon dioxide. Regeneration of silica gel is possible by depressurizing and evacuating the silica gel beads during the desorption phase.

\section{Carbon Molecular Sieve}

Oxygen concentrators typically use the properties of a selected type of desiccant to adsorb molecules from compressed air, allowing concentrated levels of a selected gas (usually nitrogen or oxygen) to be produced. ${ }^{7}$ Our commercially available CMS is specifically designed to primarily adsorb oxygen molecules, while other desiccants such as zeolite are designed to primarily absorb nitrogen molecules. ${ }^{10}$ Additionally, different batches of CMS can have differing adsorption characteristics. ${ }^{8}$ The manufacturer of the CMS used in this design is Sacred Hua Lin, product number CMS-220, provided by On-Site Gas Systems. Carbon molecular sieve is a microporous mineral with a bidisperse pore structure made of interlocking ion rings. ${ }^{10}$ The porous arrangement of CMS creates a large surface area to volume ratio that allows for a high rate of adsorption. ${ }^{11}$ The rate of uptake is determined by the structure of the micropores and pressure.

A study done at Adsorption Research, Inc. by Dr. Kent S. Knaeble shows that CMS has strong selectivity in oxygen uptake over other air molecules. ${ }^{12}$ Lithium-exchanged (LS LiX) zeolite shows selectivity towards adsorption of nitrogen. In a study using air composed of nitrogen, oxygen and argon, CMS has stronger selectivity for oxygen and argon versus nitrogen; while LS LiX zeolite had stronger selectivity towards nitrogen versus oxygen and argon. The Langmuir Parameter was determined to quantify the amount of gas adsorbed on the desiccant in terms of partial pressure. ${ }^{12}$ The Langmuir model is the method typically used in PSA simulations and is based on these following postulates:

- The atom or molecule adsorbed is contained at a particular, local site. 
- A site can only contain one atom or molecule.

- The absorption energy is identical for each site.

- No interaction between adjacent molecules occurs.

The equation for this model was derived from the relation between occupied and unoccupied molecule sites due to mass action considerations. Adsorbate loading $q$ in $\mathrm{mmol} / \mathrm{g}$ is given by the following equation:

$$
q=\frac{A P}{1+B P}
$$

where $P$ is the pressure (bar) in the desiccant bed. The Langmuir Parameters for LS LiX zeolite adsorption of oxygen were 0.13342 and 0.02668 for $\mathrm{A}$ and $\mathrm{B}$, respectively. For CMS, the adsorption parameters of oxygen were 0.28460 and 0.15330 , respectively. This indicates that LS LiX zeolite selectivity of oxygen is less than CMS. Testing was also done to determine duration of time for $90 \%$ saturation. CMS saturation of oxygen occurred after $31 \mathrm{~s}$ while saturation of nitrogen occurred after 282s. Saturation of LS LiX zeolite occurred after $1.5 \mathrm{~s}$ for both nitrogen and oxygen. ${ }^{12}$ Thus, for the design of this concentrator CMS has more desirable characteristics than LS LiX zeolite.

\section{Design}

The proposed design of the oxygen concentrator is a VPSA system composed of a regenerative blower that forces pressurized air through a series of beds packed with adsorbent material (Figure 1). A vacuum pump depressurizes the beds, regenerating the CMS and silica gel desiccant for repeated use. To sustain continuous flow there are two sets of desiccant beds. The regenerative blower sends pressurized air through a three way valve through one of the two silica gel beds, where water vapor is adsorbed. Once through the silica gel bed, air enters the CMS bed. Here, the air pressure allows oxygen to be adsorbed by the CMS. Nitrogen and non-adsorbed oxygen (bypass oxygen) pass through the CMS and out through a check valve into the environment. Once the maximum saturation level is reached, the valve redirects the pressurized air into the second set of beds. The vacuum pump depressurizes the saturated silica gel and CMS, regenerating the silica gel and extracting oxygen from the CMS. The recovered oxygen released from the CMS can be captured and used for medical purposes. Once the beds are fully regenerated and the second set of beds saturated, the valve will redirect the air again to the first set of beds. The VPSA system allows for oxygen rich air to be produced continuously. Active components of the system, such as the valves, regenerative blower and vacuum pump, are controlled by an electronic control system (Figure 2). The timing of the pressurization and depressurization swing is controlled automatically by integrating recovery oxygen, bypass oxygen, and relative humidity feedback from sensors into the controls. Materials used for the piping and beds of desiccant are a combination of PVC and ABS. These materials were chosen for cost and availability.

\section{Test Design}

Due to budgetary constraints and ease of experimentation the test design contained one set of desiccant beds, and a piston compressor (Figure 3). Through these experiments we aimed to determine the ideal operational parameters for the CMS and silica gel beds with respect to pressure and flow rate so as to specify a suitable regenerative blower. Pressure sensors installed in the pressurized air tank and in the silica gel bed monitored pressure levels to ensure the desired pressurization was

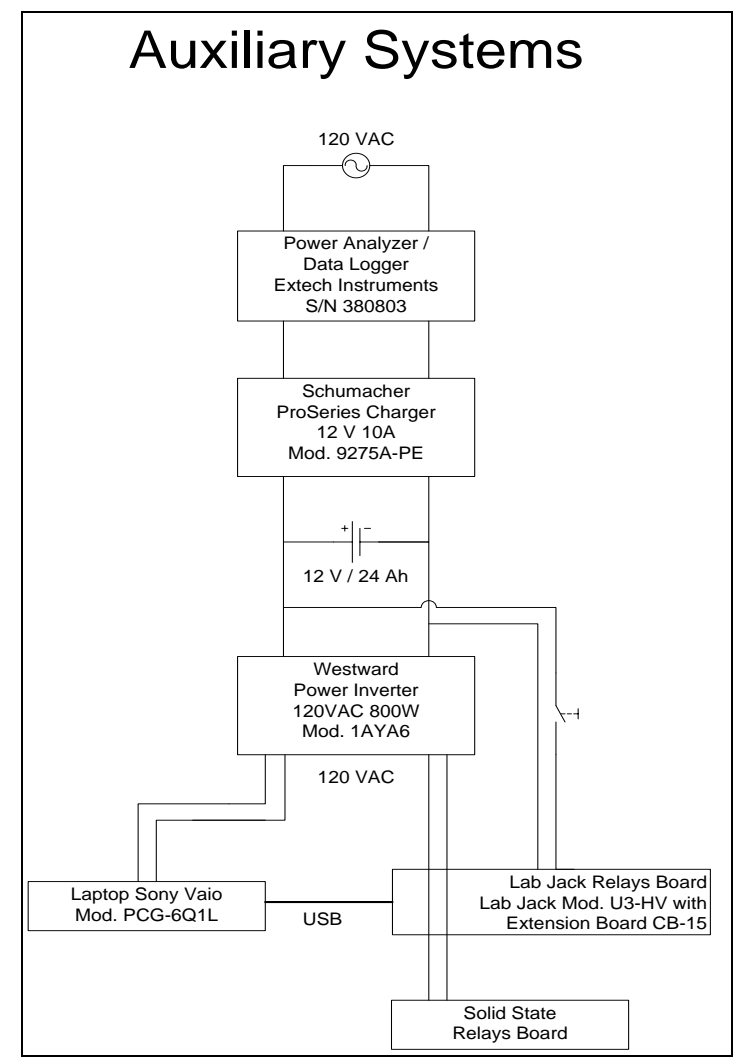

Figure 2: Automated control of VPSA system including auxiliary power supply, logging and management. 
accomplished. The relative humidity (RH) of the air entering the CMS bed was monitored by an RH sensor installed in between the silica gel and CMS bed. Oxygen sensors monitored the bypass oxygen and the recovery oxygen. Bypass air exited the CMS bed through a release valve and flow meter at a maximum flow rate of $11 \mathrm{LPM}$. The recovered oxygenated air exited the beds through the silica gel bed, release valve, flow meter, then vacuum pump at a flow rate of 6 LPM, where the recovery oxygen sensor was located. The manipulated variables were adsorption time of air and pressure in the beds.

Adsorption time is the variable that describes amount of time that the pressurized air is flowing through the CMS bed. VPSA system swing time depends on how long it takes for the CMS bed to become saturated, which in turn depends on the rate at which CMS adsorbs oxygen. By measuring bypass oxygen concentration levels the optimal adsorption time can be determined.

Adsorption pressure is the pressure in the CMS bed during the adsorption phase. The Langmuir model indicates that oxygen will have a greater affinity to adsorb to CMS under increased pressure conditions. Similar to residence time, this would suggest that there may be an optimal adsorption pressure at which oxygen uptake is maximized while minimizing energy requirements. Pressure level and residence time are the variables manipulated in the testing phase (Figure 4).

The tested parameters were pressure and adsorption/desorption time. The first series of tests increased initial bed pressure by increments of $30 \mathrm{kPa}$, starting at $30 \mathrm{kPa}$ gage up to a maximum of $300 \mathrm{kPa}$ gage. At each pressure level, various adsorption times were tested starting with 30 s, increasing by 30 s up to a maximum of 300 s. In all, 118 tests were conducted in this series.

All valves, the compressor, and vacuum pump were controlled by a LabJack® controller via relay boards (Figure 4). The controller processed input from the oxygen sensors, pressure transducers, and relative humidity/temperature sensor. Data was gathered in a laptop for further processing by MATLAB.

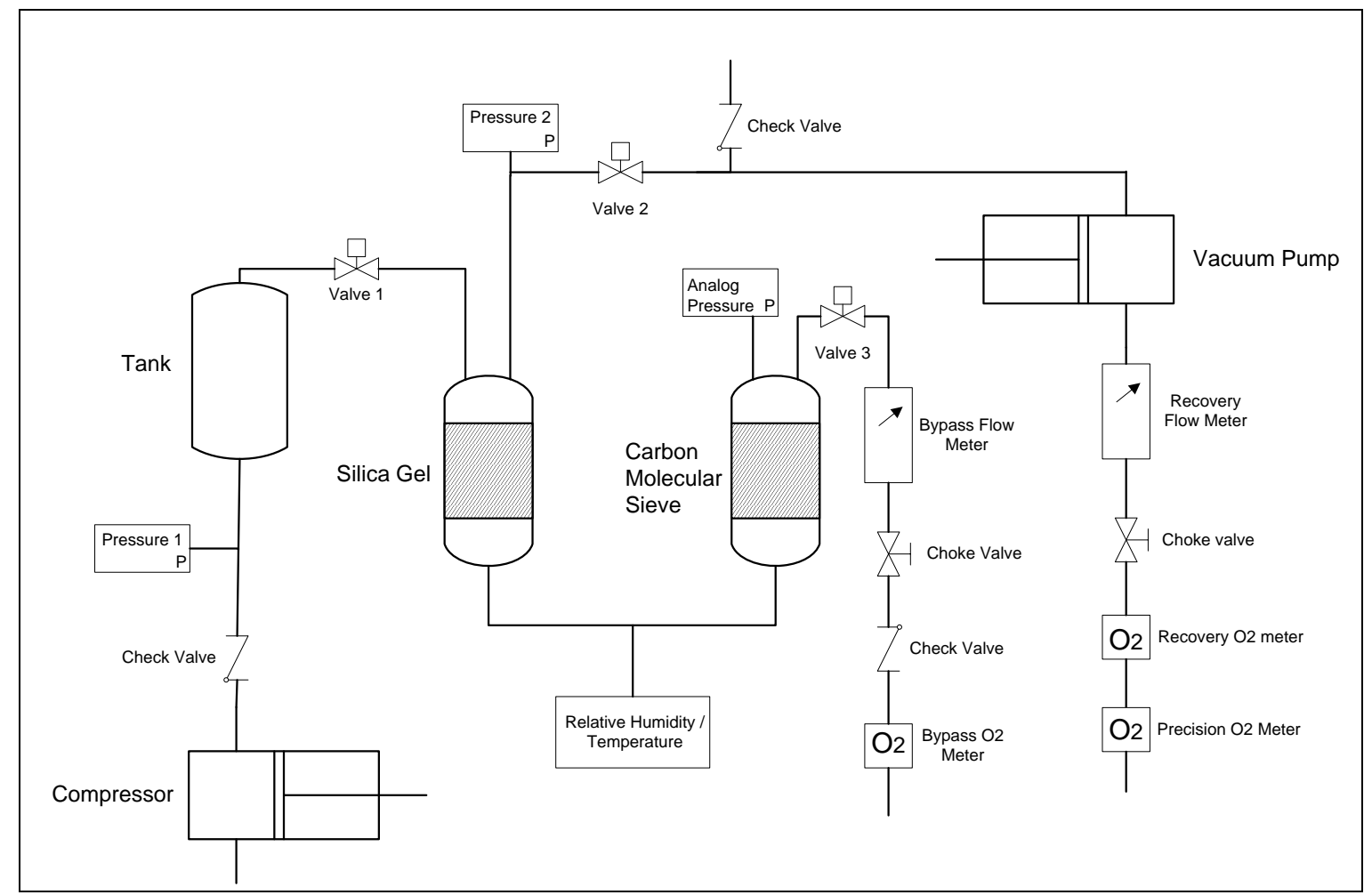

Figure 3: A representation of the prototype VPSA system. The compressor and tank pressurizes air from the atmosphere into the beds of silica gel and carbon molecular sieve, which adsorb water vapor and oxygen, respectively. Nitrogen and other trace gases exit through a check valve and bypass flow meter. When the desiccant becomes saturated Valve 1 is closed and the beds are depressurized with a vacuum pump, regenerating the desiccants. The resulting exhaust from the vacuum pump is oxygenated air and water vapor. 


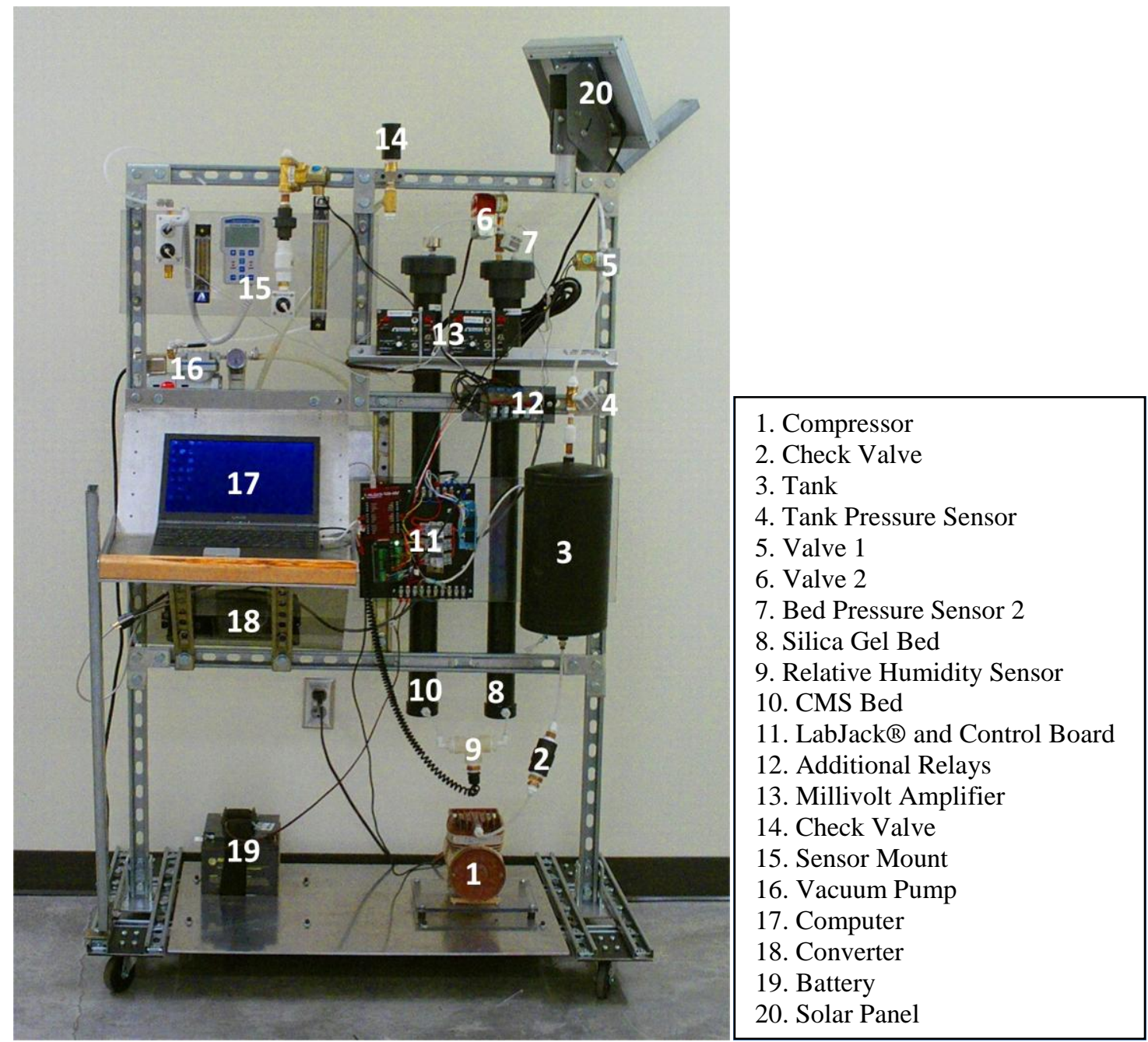

Figure 4: Test design with labeled parts.

\section{Results}

Figure 5 shows the actual pressure maintained by the test apparatus. The pressure fluctuates as Valve 1 opens and closes, allowing pressurized air to enter the beds. The average pressure was used to analyze the maximum oxygen recovery achieved for each test. The figure displays a maintained pressure range of $82 \mathrm{kPa}$ to $133 \mathrm{kPa}$, resulting in an average pressure of $105.5 \mathrm{kPa}$. 


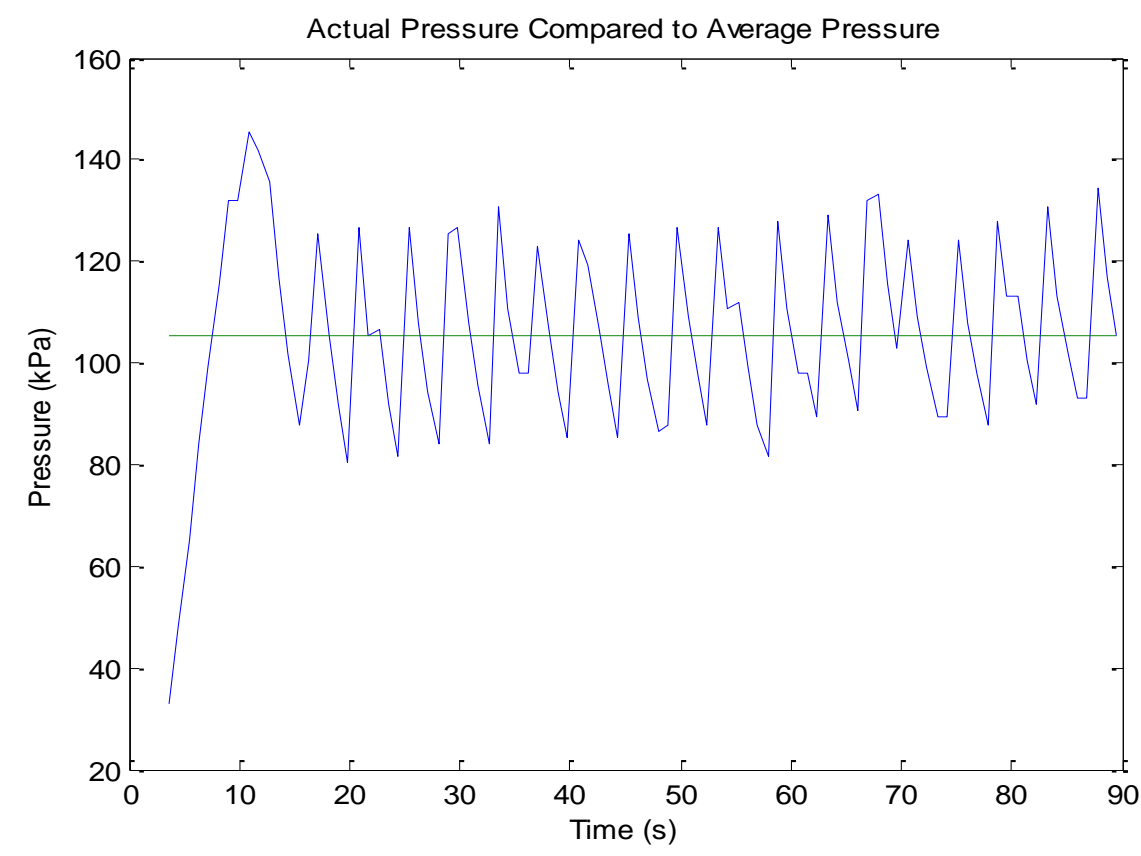

Figure 5: Average pressure of the fluctuating pressure swings. The fluctuations occur due to the opening and closing of Valve 1. The average pressure used to analyze the data is represented by the straight line.

Figure 6 shows test results for a 90s adsorption period and a 90s recovery cycle. The achieved maximum oxygen recovery from this test was $34.5 \%$. The shapes of the curves were characteristic for all tests conducted. For this test the time from depressurization to maximum oxygen recovery was $47 \mathrm{~s}$.

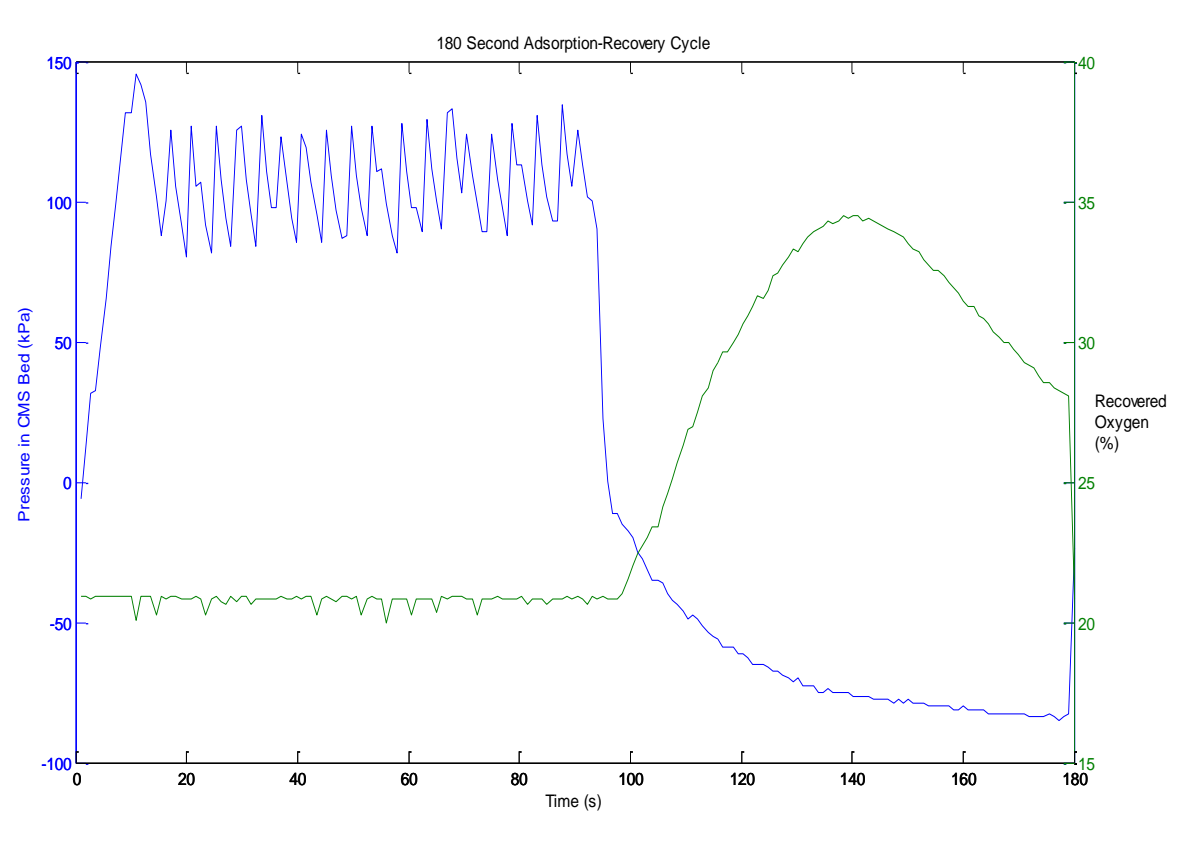

Figure 6: Test results for a $180 \mathrm{~s}$ uptake/recovery cycle. An average pressure of $150 \mathrm{kPa}$ was maintained during the 90s uptake cycle, followed by an oxygen recovery of 90s. The maximum oxygen recovery point was $34.5 \%$. 


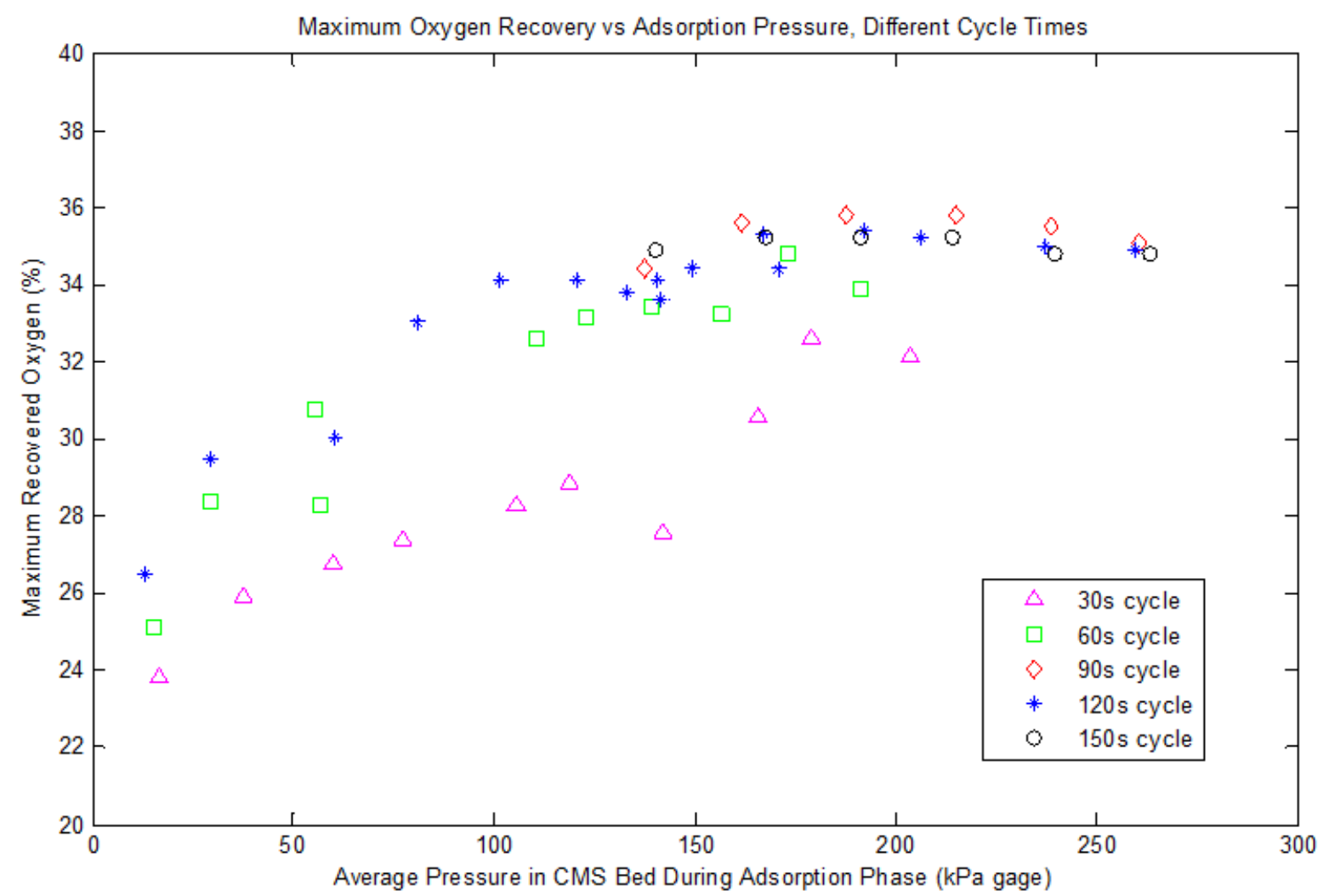

Figure 7: Oxygen recovery of 30s, 60s, 90s, 120s, 150s adsorption phases. Increasing pressure increases oxygen adsorption up to a maximum between $180 \mathrm{kPa}$ and $220 \mathrm{kPa}$. If pressure is increased further the adsorption of CMS appears to become less specific for oxygen. Increasing adsorption time improves oxygen recovery with a maximum at 90 second cycle time. If adsorption time is further increased the oxygen recovery suffers.

Figure 7 shows the correlation between increased adsorption time and maximum oxygen recovery. In general, oxygen recovery increases with higher pressure and adsorption times up to a maximum between $180 \mathrm{kPa}$ and $220 \mathrm{kPa}$. Maximum oxygen concentration of $35.8 \%$ occurs at $188 \mathrm{kPa}$ gage during the $90 \mathrm{~s}$ phase cycle. The desired oxygen concentration of $40 \%$ was not achieved in this round of experimentation.

\section{Conclusion}

The low-power, CMS-based oxygen concentrator may be able to serve as a source of medical oxygen for manned spaceflight and hospitals in developing countries. While the goal of $40 \%$ oxygen concentration was not achieved at this time, the tests indicate the desired oxygen concentration may be possible with further experimentation, namely by increasing bed size.

Direct correlations between adsorption time, bed pressure, and recovered oxygen have been established within the boundaries of this project. Time for CMS to become saturated is about 90 seconds in the current configuration once sufficient pressures have been reached. Pressure levels in the CMS bed do not seem have a significant effect on maximum oxygen levels beyond the $180 \mathrm{kPa}$ (gage) range, which opens the possibility of regenerative blowers replacing the compressor in this system.

Prospective improvements to the test apparatus include the addition of a pressure regulator to supplement the combination of compressor and air tank. Implementation of a pressure regulator will eliminate the large pressure swings currently occurring during the adsorption cycle. We believe that a more stable and precise pressure will lead to more repeatable levels of oxygen recovery. Once an optimal adsorption pressure is established, an appropriate regenerative blower may be sourced and installed. Further experimentation is needed in order to determine whether saturation time of CMS can be shortened by increasing flow rates or if it is dependent on total air volume flowing 
through the bed. Presently a blower with the following specifications would seem ideal: Operating Pressure 180kPa and $20 \mathrm{LPM}$ volume at $180 \mathrm{kPa}$, rated for continuous operation. Expanding the test apparatus by a second set of silica and CMS beds and installing a suitable blower will allow for continuous operation. At that time actual energy requirements could be quantified with the power analyzer and compared to existing systems.

Increasing bed size may increase total oxygen adsorption, thereby increasing recovered oxygen. Only through further experimentation will it be determined whether increased CMS volume, in combination with other parameter variations, could push the recovered oxygen over the target threshold of $40 \%$.

\section{Acknowledgements}

The authors thank Dr. John Graf at the NASA Johnson Space Center, Mr. Guy Hatch and Mr. Andrew Terwilliger at On-Site Gas Systems, and Mr. Jayaraman Ambalavanan at TDA Research, for their significant contributions to this project. Funding support was provided by On-Site Gas Systems of Newington, CT.

\section{References}

1 "Development of Pressure Swing Adsorption Technology for Spaceflight Medical Oxygen Concentrators" NASA Human Research Roadmap <http://humanresearchroadmap.nasa.gov/Tasks/?i=801.

2 Johannigman, Jay A., "Evaluation of Oxygen Concentrators at Altitude", NASA Task Book, Grant/Contract No. NCC 9-58-SMS00005 10 Jul 2009.

${ }^{3}$ Li, L., "High Energy Density Lithium Air Batteries for Oxygen Concentrators," NASA SBIR 2010 Solicitation, 3 Sept. 2010. <http://sbir.gsfc.nasa.gov/SBIR/abstracts/10/sbir/phase1/SBIR-10-1-X12.04-8499.html.

${ }^{4}$ Seiler, B., Jeffs, W., and Nelson, C., "University Of Maryland Researchers To Develop A Computer-Based Guide For Handling Medical Emergencies In Space," University of Maryland Medical Center. 4 Aug. 2005. $<$ http://www.umm.edu/news/releases/nasa.htm.

${ }^{5}$ Bose, A., "Health for All by 2000: Broken Promises," Economic and Political Weekly, Vol. 36, No. 11, 17-23 March 2001, pp. 905-907.

${ }^{6}$ Makhni, S., "Diagnostics and the Developing World: Vital Technology that Could Help Level the Playing Field of Global Healthcare," MIT Undergraduate Research Journal, Vol. 19, Spring 2010.

${ }^{7}$ Eltringham, R., "The Oxygen Concentrator," Update in Anaesthesia, Issue 1, Article 6, 1992, pp. 1.

${ }^{8}$ Jayaraman Ambalavanan, "Kinetically Controlled PSA Separation - Barrier Resistance", Master's Thesis, National University of Singapore, 2001.

${ }^{9}$ Jeong, H. D., Kim, D. S., Kim, K. I., and Song, I. K.., "Adsorption Characteristics of Nitrogen and Oxygen onto Ion-Exchanged X-Type Zeolite," Soild State Phenomena, Vol. 119, Jan. 2007. pp. 143-146.

${ }^{10}$ Mieville, Rodney L., Robinson, Ken K., "Carbon Molecular Sieves and Other Porous Carbons”, Mega-Carbon Company http://www.megacarbon.com/techlit/carmolsiv.pdf.

11 "Activated Alumina and Molecular Sieves," Axens North America, Inc.

http://www.axens.net/pdf/products/Axens_adsorbents.pdf.

${ }^{12}$ Knaebel, K. S., "Preliminary Simulation Results,” Adsorption Research, Inc., Dublin, OH. 18 Dec 2010. 